Abstract-The Pacific sand lance (Ammodytes personatus) is a small, elongate forage fish that spends much of its life buried in the seafloor. We determined that the $\mathrm{Pa}$ cific sand lance can burrow in a wide variety of sediments from silt to gravel, but it prefers coarse sand $(0.50-1.00 \mathrm{~mm}$ grain size). In the absence of coarse sand, the Pacific sand lance chooses larger grain sizes over smaller ones. These preferences are independent of light or the compaction of sediment, and therefore indicate that visual cues and ease of entry are not primary means of choosing burial substrate. Instead, we speculate that the Pacific sand lance is morphologically adapted for rapid mobility in coarse sand and that coarse sand has enough interstitial spaces to enable respiration during protracted immersion. As an obligate burrower in specific sediments, the Pacific sand lance is a good candidate for habitat-based management. Substrate maps of 3 fishing grounds in southeast Alaska where the Pacific sand lance is abundant and where habitat-based management is practiced were used to create potential habitat maps. Different geologic histories have resulted in variable amounts of preferred (sand-gravel), suitable (sand mixed with silt, cobble-boulder, or rock outcrop), and unsuitable (mud, pebble-boulder) habitat for this species among regions.

Manuscript submitted 11 November 2015 Manuscript accepted 3 August 2016.

Fish. Bull: 114:445-460 (2016).

Online publication date: 25 August 2016. doi: 10.7755/FB.114.4.7

The views and opinions expressed or implied in this article are those of the author (or authors) and do not necessarily reflect the position of the National Marine Fisheries Service, NOAA.

\title{
Burrowing behavior, habitat, and functional morphology of the Pacific sand lance (Ammodytes personatus)
}

\author{
Joseph J. Bizzarro (contact author) ${ }^{1}$ \\ Ashley N. Peterson' ${ }^{2}$ \\ Jennifer M. Blaine ${ }^{3}$ \\ Jordan P. Balaban ${ }^{2}$ \\ H. Gary Greene ${ }^{4}$ \\ Adam P. Summers ${ }^{4}$ \\ Email address for contact author: jbizzarro@mlml.calstate.edu \\ 1 School of Aquatic and Fishery Sciences \\ University of Washington \\ Box 355020 \\ Seattle, Washington 98195-5020 \\ Present address: Center for Habitat Studies \\ Moss Landing Marine Laboratories \\ 8272 Moss Landing Road \\ Moss Landing, California 95039 \\ 2 Department of Ecology and Evolutionary Biology \\ ${ }^{3}$ Washington Department of Fish and \\ Wildlife \\ 600 Capitol Way N. \\ Olympia, Washington 98501 \\ ${ }^{4}$ Friday Harbor Laboratories \\ University of Washington \\ 620 University Road \\ Friday Harbor, Washington 98250 \\ Kingston, Rhode Island 02881
}

University of California, Irvine

321 Steinhaus Hall

Irvine, California 92697
Burrowing presents biomechanical and ecological challenges but enables access to expanded trophic opportunities and protection from many predators. The selective pressures surrounding burrowing are expressed in the morphological features of burrowing animals, as in the stout forearms of moles and armadillos and in the heavily reinforced skull of caecilians and dibamids (Kleinteich et al., 2012; Rose et al., 2013). A subterranean lifestyle is uncommon for aquatic vertebrates but has been observed in a taxonomically diverse group of marine fish taxa. Flounders and skates routinely cover themselves in substrate; jawfishes, tilefishes, and garden eels excavate permanent burrows; and some fishes (e.g., Pacific sandfish, Trichodon trichodon; sand lances, Ammodytes spp.) spend a majority of their life beneath the substrate after creating a tunnel that collapses behind them. The terrestrial equivalent of this behavior is seen in the "sand-swimming" skink species (Mushinsky and Gans, 1992; Maladen et al., 2011). Penetrating friable substrates in a completely aqueous environment is fundamentally different from terrestrial sand swimming by virtue of the density of water and its potential contribution to the excavation process.

The Pacific sand lance (Ammodytes personatus) is an elongate, burrowing forage fish with a wide distribution in the eastern North Pacific and a history of taxonomic confusion. Only $A$. hexapterus, formerly the Pacific sand lance and now assigned the common name of Arctic sand lance (Orr et al., 2015 ), and $A$. personatus were considered historically as valid North Pacific species, but the number of Ammodytes species in the North Pacific region and the extent of their 
distributions have long been debated (Ohshima, 1950; Han et al., 2012; Turanov and Kartavtsev, 2014). Recent genetic and morphological evidence has resolved this issue and indicates the presence of 2 additional congeners (Orr et al., 2015). Furthermore, the only species with an expansive eastern North Pacific distribution, formerly considered to be $A$. hexapterus, was redescribed as $A$. personatus (Orr et al., 2015). The range of $A$. personatus was established from southern California to the western Aleutian Islands and may extend to the Sea of Okhotsk in the western Pacific (Mecklenberg et al., 2011; Orr et al., 2015). Ammodytes personatus mainly occurs in coastal intertidal and subtidal waters but has been reported at depths of $172 \mathrm{~m}$ (Love et al., 2005).

The Pacific sand lance is a source of energy transfer between secondary producers and upper-trophiclevel species and pelagic and benthic regions because it grazes on zooplankton in the water column and has an obligate affiliation with sediments. The structure and dynamics of nearshore ecosystems are heavily influenced by the biomass of forage fishes (Gaichas et al., 2010), and species of Ammodytes, including the Pacific sand lance, are of vital importance for the energetics and breeding success of a variety of marine mammals (Weinrich et al., 1997), seabirds (Curry et al., 2011), and fishes (Arnott et al., 2002). For instance, humpback whales (Megaptera novaeangliae) at Stellwagon Bank, Massachusetts, excavate bottom sediments at night to forage on dense aggregations of buried sand lances (Ammodytes spp.) (Friedlander et al., 2009). Off British Columbia, growth rates of rhinoceros auklet (Cerorhinca moncerata) chicks are positively correlated with abundance of Pacific sand lance (Bertram and Kaiser, 1993). Several groundfishes (e.g., starry flounder [Platichthys stellatus]; great sculpin [Myoxocephalus polyacanthocephalus] have been reported to feed on schools of Pacific sand lance as they move from foraging to burial grounds off southeast Alaska (Hobson, 1986).

Where species of Ammodytes are exploited in commercial fisheries, the associated loss of forage biomass can have ecosystem-level effects. In the North Sea, overfishing of the sand eel (A. marinus) has been linked to poor breeding success of several seabird species (Arnott et al., 2002), and the prosecution of a fishery for the sand eel has negatively impacted the breeding productivity of the population of black-legged kittiwake (Rissa tridactyla) (Frederiksen et al., 2008). Conversely, an abundance of Ammodytes species can enhance the productivity and efficiency of groundfish fisheries. For instance, when biomass of Ammodytes species is relatively high, Atlantic cod (Gadus morhua) form feeding aggregations in small, predictable areas (i.e., over burial habitat) where they can be targeted easily (Richardson et al., 2014). Given the importance of the Pacific sand lance to the trophic dynamics of nearshore systems (Beacham, 1986; Borstad et al., 2011) and current concern over ecosystem-level effects of exploiting forage fishes (Smith et al., 2011; Essington et al., 2015), determining the specific habitat and burrowing requirements of the Pacific sand lance are necessary steps toward the development of ecosystem approaches to the management of this species.

Like the sandfish (Scincus scincus), a lizard found in sandy habitats in North Africa and Southwestern Asia (Maladen et al., 2009), the Pacific sand lance is able to burrow rapidly into the substrate (Gidmark et al., 2011). It is tempting to suppose that this fish takes advantage of the viscosity and density of water to stir, or fluidize, the sand before burrowing; however, this behavior has not been observed. Instead, high-speed video of Pacific sand lance burrowing in the laboratory indicates that this fish dives headfirst into the sand, beating its tail and driving the head and anterior twothirds of its body underground. At this point, the buried part of its body undulates and draws the remaining part of the fish beneath the sediment (Gidmark et al., 2011). Models show that the sandfish uses substantial force to burrow into dry sand. It is not possible to extrapolate this type of movement to the Pacific sand lance because there are no data to indicate the relative ease of penetrability through dry sand and sand inundated with water. Results from isolated laboratory and field studies, however, indicate that burial preferences range from fine to very coarse sands (Pinto et al., 1984; Haynes et al., 2007; Robinson et al., 2013). If these burial preferences can be refined further through more complete testing, this information could 1) be used in habitat-based management plans for Pacific sand lance and 2) may reveal morphological and behavioral adaptations that explain the preference of Pacific sand lance for a particular grain size or sizes.

The Pacific sand lance is an accomplished burrower that spends a large percentage of its time in sediment of unknown characteristics. Because it is an important forage fish with a strong benthic association, the habitat preferences of this species has direct implications for the development of ecosystem approaches to management and conservation. This fish is also an excellent model for studying locomotion by an elongate, anguilliform burrower in an aquatic environment. The goals of our study were fivefold: 1) to assess the grain sizes, ranging from silt to very fine gravel, that are potential burial habitats for Pacific sand lance; 2) to determine whether Pacific sand lance prefer substrates of a particular size; 3 ) to use lighting and sediment compaction to gain insight into the factors that favor the selection of a burial substrate; 4) to use field sampling and habitat mapping to link sediment preferences of the Pacific sand lance in the laboratory with substrate associations in the field; and 5) to reveal specialized morphological features for burrowing.

\section{Materials and methods}

\section{Data collection}

Pacific sand lance were collected at Jackson Beach, San Juan Island, Washington, $\left(48.520^{\circ} \mathrm{N}, 123.011^{\circ} \mathrm{W}\right)$. Fish 


\section{Table 1}

Size range, Wentworth (1922) grade, and phi $(\phi)$ scale of uniform sediment types used in laboratory experiments to determine the preferred habitat of Pacific sand lance (Ammodytes personatus). Experiments were conducted in 2010 and 2012.

\begin{tabular}{lcc} 
Size range & Wentworth grade & Phi scale \\
\hline $2.0-4.0 \mathrm{~mm}$ & Very fine gravel & -1 to -2 \\
$1.0-2.0 \mathrm{~mm}$ & Very coarse sand & 0 to -1 \\
$0.5-1.0 \mathrm{~mm}$ & Coarse sand & 1 to 0 \\
$0.25-0.5 \mathrm{~mm}$ & Medium sand & 2 to 1 \\
$125-250 \mu \mathrm{m}$ & Fine sand & 3 to 2 \\
$62.5-125 \mu \mathrm{m}$ & Very fine sand & 4 to 3 \\
$3.9-62.5 \mu \mathrm{m}$ & Silt & 5 to 4
\end{tabular}

were captured in a boat-deployed bag seine in subtidal and intertidal waters (depths $\leq 10 \mathrm{~m}$ ) during the summers of 2010 and 2012 . Within an hour of capture, individual fish in good condition were taken to the University of Washington's Friday Harbor Laboratories, where they were maintained in an 1136-L (300-gallon) aquarium with running seawater and a mixture of sediments to enable burrowing. The entire size range of sampled Pacific sand lance (5.0-14.5 cm in total length [TL]), that corresponded to juveniles, subadults, and adults (Wyllie-Echeverria ${ }^{1}$, was used to determine the burrowing capabilities of this species. However, specimens used in sediment preference trials were restricted to individuals corresponding to subadult sizes (8.5-11.0 cm TL) to account for possible scaling effects and because they were the dominant size class in catches. All laboratory experiments were conducted within a month after fish were collected. Approximately 300-500 individuals were maintained throughout the experiments and periodically fed with locally caught mysids and copepods. Only fish that appeared to be in good physical condition (i.e., were active, had no obvious abrasions or injuries, and their fins were intact) were used in experimental trials.

Marine sediments were collected from local beaches throughout San Juan Island to obtain a variety of grain sizes. Sediments were dried and sorted into 7 uniform grain sizes ranging from silt $(0.4 \mathrm{~mm})$ to very fine gravel $(4.0 \mathrm{~mm})$ by using a Ro-Tap sediment analyzer (W. S. Tyler, Mentor, Ohio) (Table 1). For all laboratory trials, sediments were placed in paired aluminum trays with a volume of $0.014 \mathrm{~m}^{2}$ and a depth of approximately $15 \mathrm{~cm}$ that corresponded to the maximum depth at which Pacific sand lance have been observed locally. A dark, plastic divider measuring 7.5 $\mathrm{cm}$ in width separated the trays to minimize an arbitrary sediment choice.

\footnotetext{
${ }^{1}$ Wyllie-Echeverria, T. 2010. Personal commun. Friday Harbor Laboratories, Univ. Wash., Friday Harbor, WA 98250.
}

\section{Laboratory experiments}

To determine the grain sizes that represent potential burial habitats, 10 fish were placed in a 76-L (20-gallon) aquarium with running seawater and a uniform substrate consisting of 1 of the 7 grain sizes (described in Table 1). Experimental fish were netted out of the larger holding tank after the sediment was stirred to mobilize burrowed individuals. Seawater was fed directly through a screen placed over the top of the tank so that water flow did not create bottom currents that could influence burrowing. Fish were not introduced into the tank until the water was no longer turbid. Individuals spanning the entire observed size range of the species were used in each trial, periodically observed, and continuously filmed for 6 consecutive daylight hours. The Pacific sand lance typically shelters within an hour of exposure to a suitable sediment type (Pinto et al., 1984). If at least one individual burrowed into sediment of a particular grain size during the trial period, sediment suitability was verified and the grain size was advanced for use in experiments of preferred sediment types.

For experiments on sediment preference, 50 individuals were introduced into a 76 -L tank with paired sediment types configured as previously indicated. Fish were allowed to acclimate for $4 \mathrm{~h}$, after which covers were placed over the sediment trays, all mobile individuals were removed, and the tank was drained. The number of buried fish in each sediment type was then recorded and all fish in good condition were returned to the holding tank. Daytime trials $(n=41)$ were conducted between 1100 and $1700 \mathrm{~h}$, and illumination was provided simultaneously by sunlight and ambient room lighting. Nighttime trials ( $n=16$ ) occurred between 2300 and $0300 \mathrm{~h}$ in complete darkness. Eight replicates were planned for all trials; however, diurnal trials involving medium sand-a grain size that was largely avoided by fish-consisted only of either 5 or 6 replicates because of time and logistical constraints (e.g., condition of captive Pacific sand lance).

Preferred sediment was determined by using replicated $G$-tests of goodness of fit from an expected 1:1 ratio (Connallon and Jabukowski, 2009; McDonald, 2009). A $G$-test of goodness of fit was first conducted for each replicate in a comparison of paired sediments (individual test). To determine whether all of the data from the different experiments fit the expected 1:1 ratio, the individual $G$-values from these replicates were then added to assess the significance of the aggregate $G$-value (total test). A pooled $G$-test was then conducted by adding all the observations among experiments and by testing the resulting $G$-value (pooled test). Finally, a $G$-test of independence was used to determine whether the individual trials had significantly different relationships from one another (heterogeneity test). The totality of these results was synthesized to determine burrowing preference and to explain burrowing behavior.

Laboratory experiments were combined with the testing of compaction by using resin models of Pacific 
sand lance to determine whether burrowing preference and penetration force of the Pacific sand lance differed in uncompacted and compacted sediments. Full compaction was achieved by vibrating a plexiglass plate over one of the paired sediment trays until readings, made with a penetrometer (Forestry Suppliers Inc., Jackson, MS), peaked. In experiments of preferred sediments, compacted and uncompacted sediments consisting of the 4 largest grain sizes were paired, as described in Table 1, and were conducted (only) during daylight hours (Table 1). Models of subadult Pacific sand lance were created by making dental wax (President light body ${ }^{2}$; Coltene, Altstätten, Switzerland) molds of euthanized fish and then filling the molds with Spurr resin. These models were pressed into inundated sediment until a third of the body was covered, corresponding with the penetration stage of burial (Gidmark et al., 2011). Force was calculated with a force gauge (MTS Systems Corp., Eden Prairie, MN) at increments of 1.0 $\mathrm{mm}$, and 5 replicates were conducted for each tested grain size and compaction level.

The force necessary to penetrate uncompacted and compacted sediments of different grain sizes was plotted against penetration depth, and the data were log-transformed to achieve linearity. Slopes of the relationship between force and penetration depth were compared by using a 2-way analysis of variance (ANOVA), with compaction and sediment size as independent variables. Where ANOVAs were significant, a Tukey's honestly significant difference test was run to determine the groups that contributed to these differences.

\section{Field collections}

A comprehensive fish and sediment sampling effort was conducted at the central San Juan Channel sand wave field, a region where bottom currents have shaped the seafloor geomorphology into a series of successive crests and troughs at depths of 60-80 m to determine sediment associations of Pacific sand lance in offshore waters. Twenty-one target sites with a minimum separation distance of $70 \mathrm{~m}$ were chosen randomly throughout the sand wave field, excluding areas near cable crossings (Fig. 1). By using the RV Centennial, fish and sediment were collected with a Van Veen bottom grab, a clamshell-type sampler with long lever arms and sharp cutting edges that enable deep (up to $22 \mathrm{~cm}$ ) penetration into seafloor sediment. The Van Veen grab has a rapid, powerful closing mechanism, with overlapping flaps, that allows the jaws to excavate 0.12 $\mathrm{m}^{2}$ of relatively undisturbed sediment while preventing the loss of sediment or fish. This sampling method has been extremely successful for obtaining significant numbers of live sand eel and representative seafloor sediment (Freeman et al., 2004).

\footnotetext{
2 Mention of trade names or commercial companies is for identification purposes only and does not imply endorsement by the National Marine Fisheries Service, NOAA.
}

Samples were collected at each site during both nighttime and daytime low-tide periods; nighttime sampling was conducted during 2000-2400 on 6 November 2006, and daytime sampling was conducted during 1030-1430 on 7 November 2006. The nighttime samples were collected as close to the target sites as possible given drift and current conditions, and the actual vessel coordinates were recorded when the grab hit bottom. These coordinates then became the target sites for the daytime samples. After each sample was retrieved, all fish were removed and frozen, and a 400-600-mL subsample of sediment was collected. Fish were later counted, measured, and dissected to determine sex and maturity stage (after Macer, 1966; Nelson and Ross, 1991). Sediment was dried and sorted by using a Ro-Tap sediment analyzer, as previously described, and the total weight and relative proportion of each grain size was recorded (according to the method of Wentworth, 1922). Data were evaluated for normality and homoscedasticity, and a paired $t$-test was conducted to investigate the difference in the mean number of Pacific sand lance collected during day and night grabs that occurred at the same target locations. Field results of habitat preference were used for comparison with results from laboratory experiments.

\section{Habitat mapping}

Sediment preferences determined from laboratory experiments and field collections were applied to previously constructed seafloor-substrate maps of common fishing grounds for groundfish (especially for rockfish) off southeast Alaska (Fairweather Ground, Cape Ommaney, and Edgecumbe). Substrate maps were created during 1998-2004 by 2 of the authors (H. Greene and senior author) for use in habitat-based fishery management by the Alaska Department of Fish and Game, Sitka office. Source data included a combination of side-scan sonar and multibeam imagery. Map interpretations were verified with data from dives of a humanoccupied submersible.

The mapped depths of the Fairweather Ground and Edgecumbe fishing grounds were within the known depth range of Pacific sand lance (Love et al., 2005). The substrate map for the Cape Ommaney fishing ground, however, extended to a depth of $305 \mathrm{~m}$, well beyond the approximate maximum depth of known occurrence of Pacific sand lance (Love et al., 2005). A 175-m depth contour, therefore, was extracted from the multibeam imagery for this region and used to create a deepwater boundary. All mapping and spatial analysis were conducted in ArcMap, vers. 10.2.2 (Esri, Redlands, CA). Ostrand et al. (2005) determined that depth was the primary factor associated with offshore distribution of Pacific sand lance and that the population in Prince William Sound was largely restricted to depths $<60 \mathrm{~m}$. However, the Pacific sand lance is extremely common to depths of at least $80 \mathrm{~m}$ off the San Juan Islands, and our predictions are of potential habitat dis- 


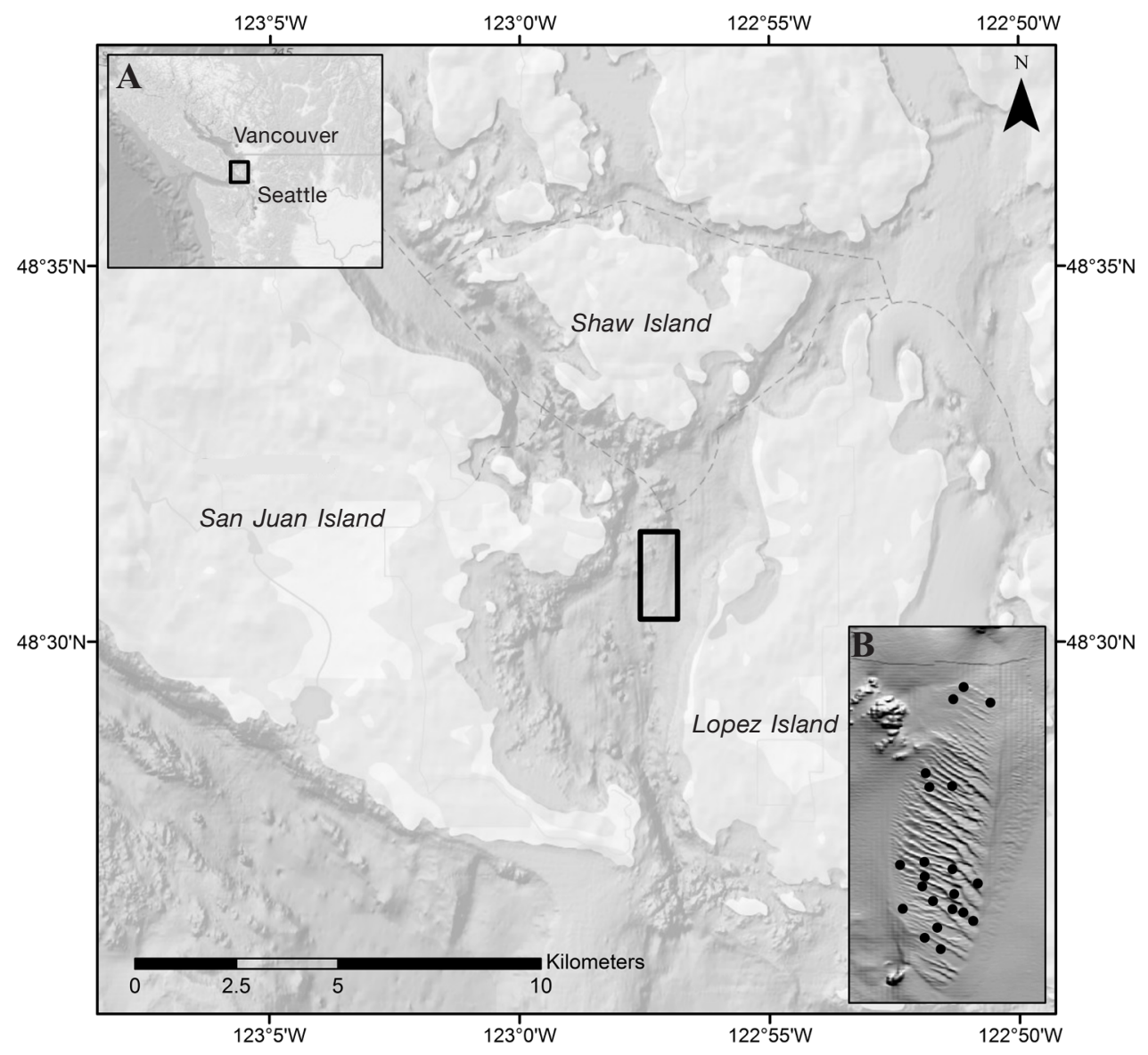

Figure 1

Location of field effort to sample Pacific sand lance (Ammodytes personatus) in the San Juan Channel, Washington, in 2006. (A) The inset map in the top left corner shows the general location of the study site among the San Juan Islands (black box) at the Pacific border between the United States and Canada (dashed line). The main map highlights the main onshore and offshore features of the region, including the location of the San Juan Channel and the sand wave field (black box) where field collections were focused. The other $(\mathbf{B})$ inset map provides a multibeam image of the San Juan Channel sand wave field; black dots indicate the sites where Van Veen grabs $(n=42)$ were made.

tribution, not fish distribution. Habitat quality, therefore, was considered to be consistent across the entire known depth range of occurrence of Pacific sand lance. Substrate data were converted into 3 potential habitat categories (preferred, suitable, unsuitable) on the basis of a synthesis of laboratory and field results.

\section{Morphology}

A neotype of $A$. personatus in the University of Washington Burke Museum collection was scanned with 5.6- $\mu \mathrm{m}$ resolution on a SkyScan 1173 micro-CT scanner (Bruker AXS GmbH, Karlsruhe, Germany) at the Karel F. Liem Bioimaging Facility at Friday Harbor Laboratories. Cross-sectional 2-dimensional images (i.e., slice data), generated across the 3-dimensional volume of the fish, were reconstructed and rendered in Amira software (FEI Co., Hillsboro, OR), and the image stack was uploaded to MorphoSource (website) as an open access resource (Godersky and Summers, 2016). A 5 -mm-by-10-mm section of skin from the lateral aspect of the body, just behind the opercular cover, was excised, dehydrated in ETOH, and dried according to the critical point drying method. The skin sample was then sputter-coated with gold-palladium and visualized with a JCM-5000 NeoScope scanning electron microscope (SEM) (JEOL, Ltd., Tokyo). Digital images were made from the combined data of the secondary electron and backscatter electron detectors. To identify structural and morphological characteristics that may contribute to burrowing success, CT- and SEM-generated images were inspected. 


\section{Table 2}

Results of experiments with paired sediment types in relation to the burrowing activity of Pacific sand lance (Ammodytes personatus). Experiments were conducted in 2010 and 2012. Data were calculated by using replicated $G$-tests of goodness of fit. Comparisons were made between medium sand (MS), coarse sand (CS), very coarse sand (VCS), and very fine gravel (VFG). In all comparisons, the grain size that contained the greater number of buried fish is listed first. The number of experimental trials $(N)$ and the number of trials in which dominant grain size had significantly more buried fish $\left(N^{*}\right)$ are given. The power of the test for each nonsignificant result is provided in parentheses.

\begin{tabular}{|c|c|c|c|c|c|c|c|c|}
\hline \multirow[b]{2}{*}{ Comparison } & \multirow[b]{2}{*}{$N$} & \multirow[b]{2}{*}{$N^{*}$} & \multicolumn{2}{|c|}{ Total } & \multicolumn{2}{|c|}{ Pooled } & \multicolumn{2}{|c|}{ Heterogeneity } \\
\hline & & & $G$ & $P$ & $G$ & $P$ & $G$ & $P$ \\
\hline \multicolumn{9}{|l|}{ Diurnal } \\
\hline CS-MS & 6 & 5 & 94.31 & $<0.001$ & 75.46 & $<0.001$ & 18.85 & 0.002 \\
\hline VCS-MS & 5 & 5 & 166.48 & $<0.001$ & 152.39 & $<0.001$ & 14.09 & 0.007 \\
\hline VFG-MS & 6 & 4 & 29.28 & $<0.001$ & 13.94 & $<0.001$ & 15.34 & 0.009 \\
\hline CS-VCS & 8 & 5 & 75.01 & $<0.001$ & 11.78 & $<0.001$ & 62.23 & $<0.001$ \\
\hline CS-VFG & 8 & 6 & 126.73 & $<0.001$ & 77.54 & $<0.001$ & 49.19 & $<0.001$ \\
\hline VCS-VFG & 8 & 2 & 69.33 & $<0.001$ & $<0.01$ & $0.957(5)$ & 69.33 & $<0.001$ \\
\hline \multicolumn{9}{|l|}{ Nocturnal } \\
\hline CS-MS & 8 & 6 & 79.31 & $<0.001$ & 73.76 & $<0.001$ & 5.55 & 0.593 \\
\hline CS-VCS & 8 & 0 & 7.98 & $0.435(48)$ & 0.22 & $0.636(8)$ & 7.76 & $0.354(49)$ \\
\hline
\end{tabular}

\section{Results}

\section{Laboratory experiments}

Pacific sand lance were capable of burrowing into all 7 provided sediment types (see Table 1). However, in the smaller grain sizes (silt-fine sand), motility was considerably reduced and fish soon reoriented themselves so that their heads were exposed. Large individuals, corresponding to adult sizes, were more likely to burrow into the larger grain sediments, whereas more small individuals (juveniles) penetrated the smaller grain sediments.

During daylight hours, Pacific sand lance preferred coarse sand to all other sediment types (total $G$-value, pooled $G$-value; Table 2 ). Very coarse sand was selected significantly more than medium sand and significantly more than very fine gravel on the basis of the total, but not pooled, $G$-test. Correspondingly, only 2 individual tests yielded significant results and supported a preference for very coarse sand over very fine gravel, and the total number of buried individuals was nearly identical ( $n=174$ and $n=173$, respectively). A significantly greater number of fish burrowed into very fine gravel than into medium sand (total $G$-value, pooled $G$-value; Table 2), which was largely avoided in all trials. Individual $G$ tests generally were consistent with the results from total and pooled tests; however, heterogeneity $G$-tests for all paired-preference trials indicated significant variation among individual trials in the observed ratio of burrowed individuals (Table 2).

At night, Pacific sand lance maintained a strong preference for coarse over medium sand, but no preference was found for either coarse sand or very coarse sand (Table 2). The total number of fish buried in coarse $(n=147)$ and very coarse $(n=139)$ sand was similar at night, and no individual tests revealed a significant preference for either grain size. The power to detect a significant difference was, however, low for these comparisons (Table 2). For both paired trials, results of the heterogeneity $G$-test indicated that results of individual experiments were consistent (Table 2). Night experiments were restricted to sediment types that directly bounded the preferred grain size (coarse sand) determined from daytime experiments (Table 1). Therefore, very fine gravel was not included in night experiments.

The number of buried individuals among (pooled) paired-sediment preference trials further supports a preference for coarse sand over other sediment types but indicates that results of individual trials are variable. The median number of buried individuals and intertrial variability were similar for comparisons of very coarse sand and very fine gravel (daytime) and of coarse sand and very coarse sand (nighttime) (Fig. 2). Correspondingly, results of pooled $G$-tests were insignificant for these comparisons (Table 2). The greatest median number of buried fish was observed for very coarse sand, from trials in which it was paired with medium sand during the day. The most highly variable result was also that of very coarse sand (range of nearly 40 individuals), from its paired trials with very fine gravel during daytime hours (Fig. 2). The most pronounced grain-size preferences were observed between coarse sand and very fine gravel (daytime), very coarse sand and medium sand (daytime), and coarse sand and medium sand (daytime and nighttime) (Fig. 2). Obvious preferences of grain size, therefore, were evident when 


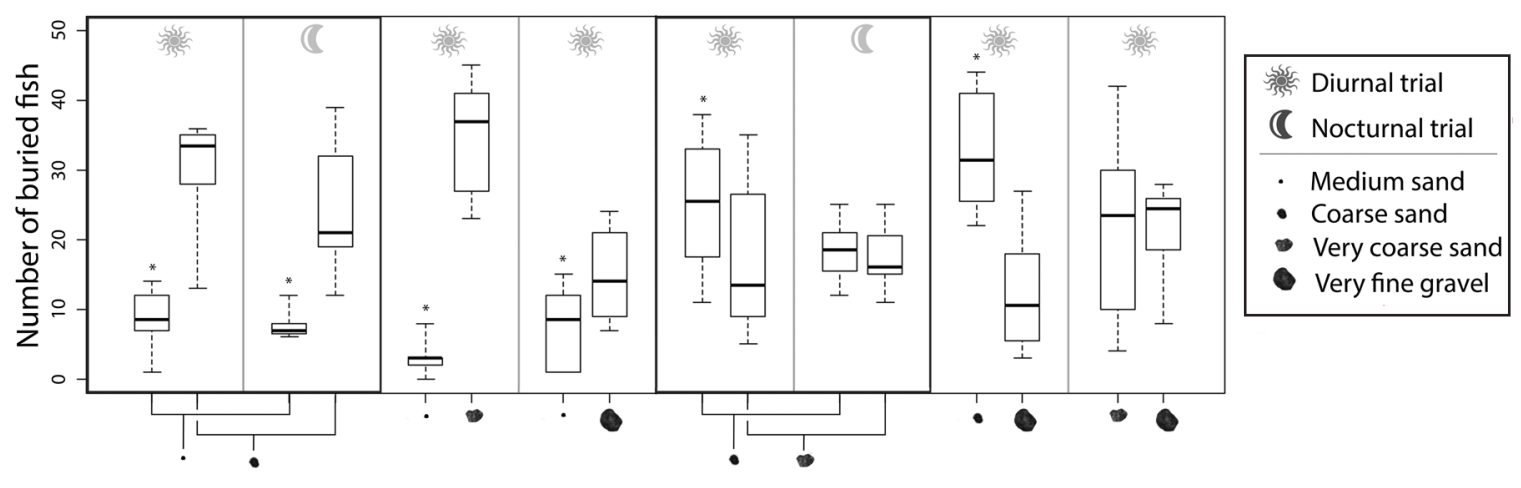

Figure 2

Box-and-whisker diagrams displaying results of pooled $G$-tests for each paired sediment preference trial conducted with Pacific sand lance (Ammodytes personatus) in 2010 and 2012. Displayed are the minimum and maximum values (whiskers), first and third quartiles (box), and median values (bold horizontal line).

all trials were considered for a comparison, but preferences were not generally consistent among trials.

The average proportion of Pacific sand lance buried among pooled experimental trials was greatest for coarse sand (Fig. 3). Among diurnal trials, the proportion of individuals buried in coarse sand was nearly $20 \%$ greater than expected by chance. Very coarse sand and very fine gravel were selected at ratios that were very close to the expected $1: 1$, whereas medium sand was selected in only about $20 \%$ of pooled trials (Fig. 3 ). Coarse sand also had the greatest average proportion of individuals buried among nocturnal trials, but the preference for this grain size was somewhat reduced compared with results from diurnal trials (Fig. 3). A similar situation was observed for very coarse sand, whereas the opposite trend was observed for medium sand (Fig. 3). Variability in the average proportion of buried sand lance among experimental trials was pronounced during diurnal trials but reduced in relation to medium sand and very coarse sand at night (Fig. 3).

Compacted sediments of all grain sizes required significantly more force to penetrate than did uncompacted sediments, as indicated by values for the mean slope of penetration depth (measured in millimeters) in relation to $\log$ force (measured in Newtons): compacted=0.071 (standard deviation [SD] 0.015), uncompacted=0.061 (SD 0.014) (Table 3). However, the mean percentage of buried fish in uncompacted (20.8\% [SD 4.8]) and compacted (21.5\% [SD 5.2]) coarse sand was similar. Correspondingly, no significant differences were detected in the selectivity for these substrates (total test: $G=8.19, P=0.22$; pooled test: $G=8.12, P=0.80$; heterogeneity test: $G=0.06, P=0.15, \mathrm{~N}=6)$. The power to detect a difference in selectivity was low, however, especially for the heterogeneity test (total $=58$, pooled $=57$, heterogeneity=5). In comparisons of burrowing force among grain sizes, smaller grain sizes generally required more force to be penetrated regardless of compaction level (mean slope: very fine gravel $=0.052$ [SD 0.007], very coarse sand $=0.059$ [SD 0.001], coarse sand=0.075 [SD 0.008 ], medium sand $=0.078$ [SD 0.017]; Table 3). The interaction between sediment size and compaction was not significant $(P=0.17)$.

\section{Field collections}

Field collections in the San Juan Channel yielded 421 Pacific sand lance during 21 daytime and 21 nighttime samples collected with a Van Veen bottom grab. Fish abundance, and therefore density, varied considerably among grab samples collected during both time periods. During the day, Pacific sand lance were caught in every grab, with a range of 2-62 individuals/grab and a median value of 13 individuals/grab (quartile 1 $[\mathrm{Q} 1]=6, \mathrm{Q} 3=18)$. By contrast, Pacific sand lance were caught less frequently ( $66.7 \%$ of grabs, $n=14)$ and in lower abundance (range $=0-26$ individuals, median $=3$, $\mathrm{Q} 1=0, \mathrm{Q} 3=11$ ) at night. Between paired samples collected at the same locations, a significantly greater mean number of individuals was collected during the day than during the night (day $=14.4$ individuals [SD 13.2]; night $=5.7$ individuals [SD 7.0]; $t=2.47, \mathrm{df}=20, P=0.023$ ). Consequently, the density of buried fish among these grabs also was much greater during the daytime (119.8 individuals $/ \mathrm{m}^{2}$ [SD 110.0]) than during nighttime (47.7 individuals $/ \mathrm{m}^{2}$ [SD 58.7]).

The deepwater population of Pacific sand lance in San Juan Channel and of subtidal individuals used in laboratory experiments were consistent in size and maturity stage. The mean size of fish captured at San Juan Channel was $8.5 \mathrm{~cm}$ TL (SD 0.6) (range $=6.5-12.3$ cm TL, $n=415)$, and $92.7 \%$ of all sampled fish $(n=356)$ were determined to be immature on the basis of internal inspection. Mean sizes and maturity stage, the determination of which requires sacrificing individuals, were not recorded for laboratory specimens col- 


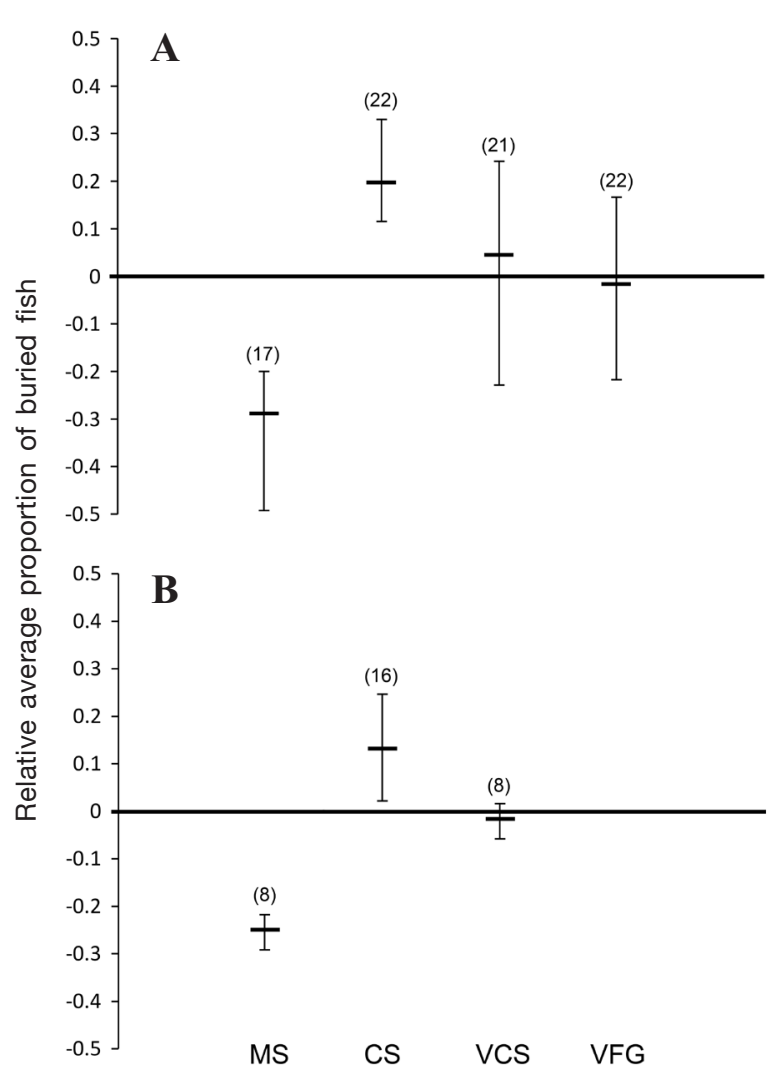

Figure 3

Average proportion of Pacific sand lance (Ammodytes personatus) buried in each grain size (medium sand [MS], coarse sand [CS], very coarse sand [VCS], and very fine gravel [VFG]) in relation to all grain sizes for (A) diurnal and (B) nocturnal trials conducted in 2010 and 2012. Horizontal bars depict the average deviation from the expected 1:1 ratio, and the zero line, therefore, is equivalent to a proportion of 0.50 . The number of replicates for each grain size is indicated in parentheses. Error bars represent first and third quartiles.

lected from intertidal and subtidal depths at Jackson Beach; however, the size range $(8.5-11.0 \mathrm{~cm}$ TL) that was used was skewed toward smaller specimens. This size range was chosen to correspond to large subadult specimens-a supposition that was validated through field sampling.

The sediment composition of the sampled sand wave field consisted primarily of coarse sand (51.4\%) and similar proportions of very coarse sand (14.5\%), gravel (16.2\%), and medium sand (17.7\%) ( $n=42$ grab samples). Very coarse sand and medium sand never contributed $>33 \%$ to sample weight, but 8 samples were composed of at least one-third gravel (Fig. 4). Fine sand (0.2\%) and silt $(0.1 \%)$ contributed trivial amounts to overall sample weight. No grain sizes larger than that of gravel were encountered. Linear regression indicated no relationship between fish abundance and the proportions

\section{Table 3}

Mean slope of the relationship between log force (measured in Newtons) and penetration depth (measured in millimeters) determined from models of different sediment types used by Pacific sand lance (Ammodytes personatus), including uncompacted (U), compacted (C), very fine gravel (VFG), very coarse sand (VCS), coarse sand (CS), and medium sand (MS). The number of experimental trials $(N)$ and standard deviation of the mean (SD) are given.

\begin{tabular}{llll}
\hline Sediment & $N$ & Slope & SD \\
\hline U & 20 & 0.061 & 0.014 \\
C & 20 & 0.071 & 0.015 \\
VFG & 10 & 0.052 & 0.007 \\
VCS & 10 & 0.059 & 0.001 \\
CS & 10 & 0.075 & 0.008 \\
MS & 10 & 0.078 & 0.017 \\
\hline
\end{tabular}

of medium sand $(t=0.718, P=0.477$, coefficient of correlation $\left.\left[r^{2}\right]=0.01, \mathrm{df}=40\right)$, coarse sand $(t=0.365, P=0.717$, $\left.r^{2}=0.02, \mathrm{df}=40\right)$, very coarse sand $(t=-0.079, P=0.717$, $\left.r^{2}=0.02, \mathrm{df}=40\right)$, or gravel $\left(t=-0.553, P=0.583, r^{2}=0.01\right.$, $\mathrm{df}=40$ ) (Fig. 4). However, limited variability in sample composition may have influenced results (Fig. 4).

\section{Habitat mapping}

The relative amount of preferred habitat for Pacific sand lance (i.e., sand; coarse sand, very coarse sand, and gravel; and sand wave fields), varied among 3 important commercial fishing grounds of southeast Alaska (Fig. 5). Preferred habitat types were predicted to be extremely rare at Cape Ommaney $(1.9 \%$ of the total mapped seafloor, $168.9 \mathrm{~km}^{2}$ ) and uncommon at Fairweather Ground (13.8\% of the total mapped seafloor, $288.0 \mathrm{~km}^{2}$ ) but common at Edgecumbe ( $36.1 \%$ of the total mapped seafloor, $538.2 \mathrm{~km}^{2}$ ). The total amount of potential habitat, consisting of habitat types that were preferred and suitable (i.e., sand mixed with mud, pebble, boulder, or rock outcrops) was greatest at Fairweather Ground (66.9\%) and similar at Cape Ommaney $(39.4 \%)$ and Edgecumbe $(39.0 \%)$. Nearly all unsuitable habitats (i.e., grain sizes $\leq 3.9 \mu \mathrm{m}$ [silt] or $>4.0 \mathrm{~mm}$ [pebble]) in all regions were composed of rocky substrates or sediment of large grain sizes (Edgecumbe: $100 \%$ of $328.4 \mathrm{~km}^{2}$; Cape Ommaney: $95.7 \%$ of $102.3 \mathrm{~km}^{2}$; and Fairweather Ground: $100 \%$ of $95.4 \mathrm{~km}^{2}$ ).

\section{Description of morphological features}

Images of the cranial and axial skeleton were produced with CT scans of the Pacific sand lance (Fig. 6, A-C). The dermatocranial elements are thin and lightly mineralized. The parasphenoid and occipital bones are well 

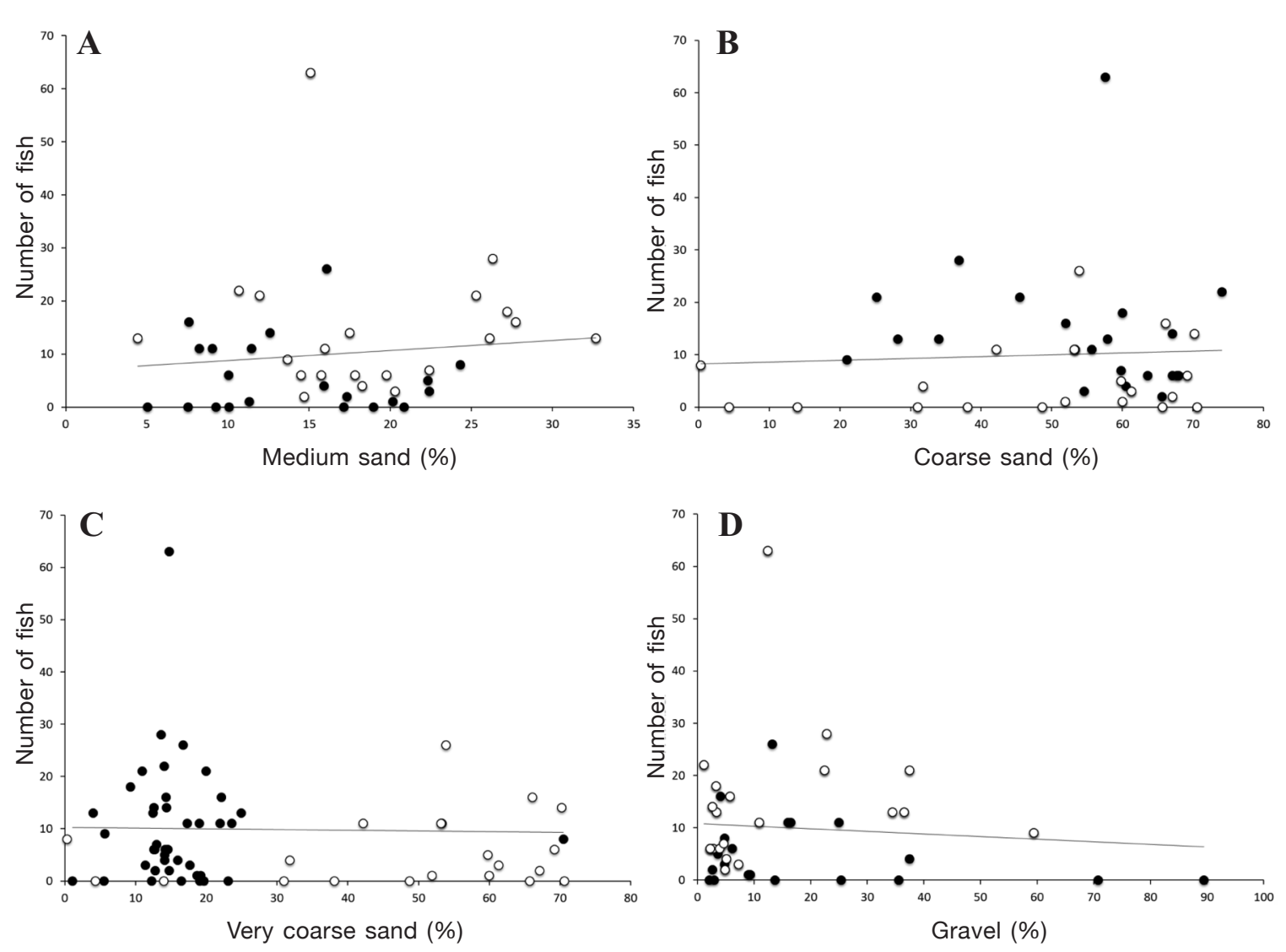

Figure 4

Relationship between percentage of grain size-(A) medium sand, (B) coarse sand, (C) very coarse sand, (D) gravel (after Wentworth, 1922) - and number of Pacific sand lance (Ammodytes personatus) captured during day (white dots, $n=21$ ) and night (black dots, $n=21$ ) field collections conducted in the San Juan Channel, Washington, in 2006.

mineralized but are not extremely dense. The skull of the Pacific sand lance does not exhibit a reduced number of bones, nor is there fusion of dermal roofing elements (Fig. 6, A-C). The lower jaw and premaxilla are well mineralized, and there are anterior flanges at the symphysis of the dentaries. These flanges are located at the most anterior part of the skeleton and would contact the substrate first in head-first burrowing. Analysis of the images from the SEM confirmed that the body scales are fused into bands oriented slightly obliquely to the dorsoventral axis (Fig. 6D). The spacing of these bands is approximately $0.25 \mathrm{~mm}$.

\section{Discussion}

In laboratory trials, the Pacific sand lance showed remarkable habitat specificity, consistently choosing to burrow into coarse sand sediment, a grain size that spans a mere $0.50 \mathrm{~mm}$. These findings refine those of a prior study in pinpointing the preferred burial grain size for this important forage species. Pinto et al.
(1984) found no difference in preference between mixtures of fine-medium and coarse-very coarse sand in a similar laboratory experiment. However, Pinto et al. (1984) maintained seawater flow to the benthos during trials, and they found that significantly more fish buried in sediment types that were oriented nearest to the incoming water than in those types that were more distant. The amount of porewater exchange in sediments, and therefore of oxygen input, is an important aspect of burial habitat of Ammodytes species (Robards and Piatt, 1999; Høines and Bergstad, 2001; Behrens et al., 2007). It is likely that the permeability of smaller grain sizes (e.g., fine to medium sand), which allow oxygen penetration of only a few millimeters under quiescent conditions (de Beer et al., 2005), was enhanced in the Pinto et al. (1984) study because of a continuous flow of benthic seawater. On the basis of our compaction results, smaller grain sizes are easier to penetrate for Pacific sand lance. Therefore, if oxygen is not a limiting factor, habitat preferences will probably shift to include smaller grain sizes (e.g., Pinto et al., 1984). By contrast, if oxygen is limiting, preferences will probably 

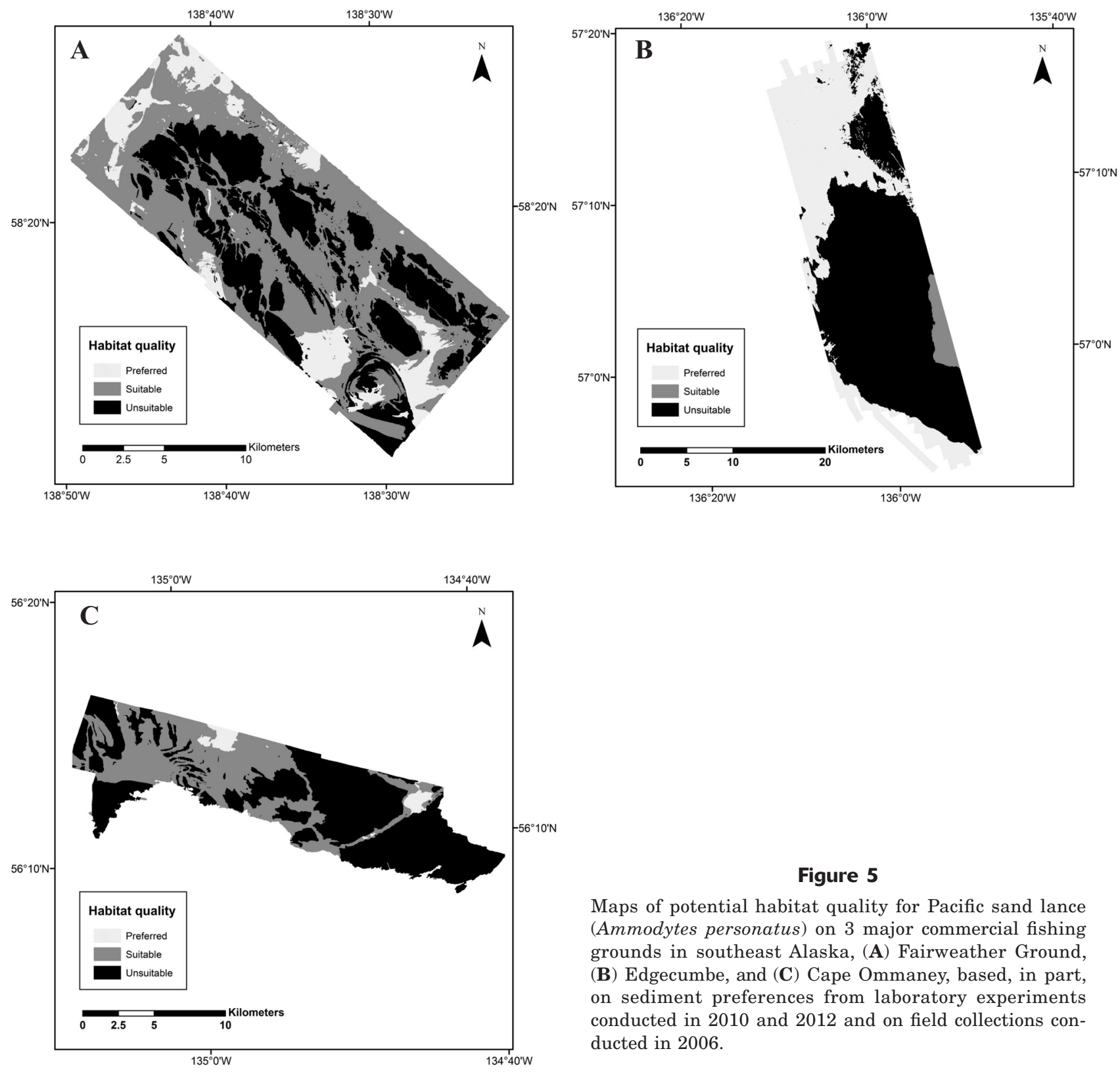

Figure 5

Maps of potential habitat quality for Pacific sand lance (Ammodytes personatus) on 3 major commercial fishing grounds in southeast Alaska, (A) Fairweather Ground, (B) Edgecumbe, and (C) Cape Ommaney, based, in part, on sediment preferences from laboratory experiments conducted in 2010 and 2012 and on field collections conducted in 2006.

shift to larger grain sizes that enable a greater degree of advective porewater exchange.

Field surveys of subtidal and inner-continental-shelf regions have also provided evidence of the association of Pacific sand lance primarily with coarse sand habitats (this study; Holland et al., 2005; Haynes et al., 2007) Coarse sand was the dominant sediment type in the San Juan Channel sand wave field, where the $\mathrm{Pa}$ cific sand lance was common and abundant; however, grain-size composition was relatively consistent among samples. Although the homogeneity of such samples limits our conclusions on preferred field sediments, other research has associated late life stages of Ammodytes species primarily with coarse sands. For example,

free-swimming juvenile and adult Pacific sand lance off British Columbia aggregate over a mixture of coarse and very coarse sand (Haynes et al., 2007). Holland et al. (2005) determined that late-juvenile sand eel in the North Sea select subtidal burial habitats consisting of medium and coarse sands, or those with moderate levels of fine gravel, and avoid habitats characterized by coarse gravel, silt, and fine sand or sites with high or low levels of fine gravel.

Uniform grain sizes were used in the laboratory to simplify comparisons of preferred sediments and to better understand their link to potential structural and morphological adaptations for burial. The Pacific sand lance has been associated with mixed sediments in sub- 


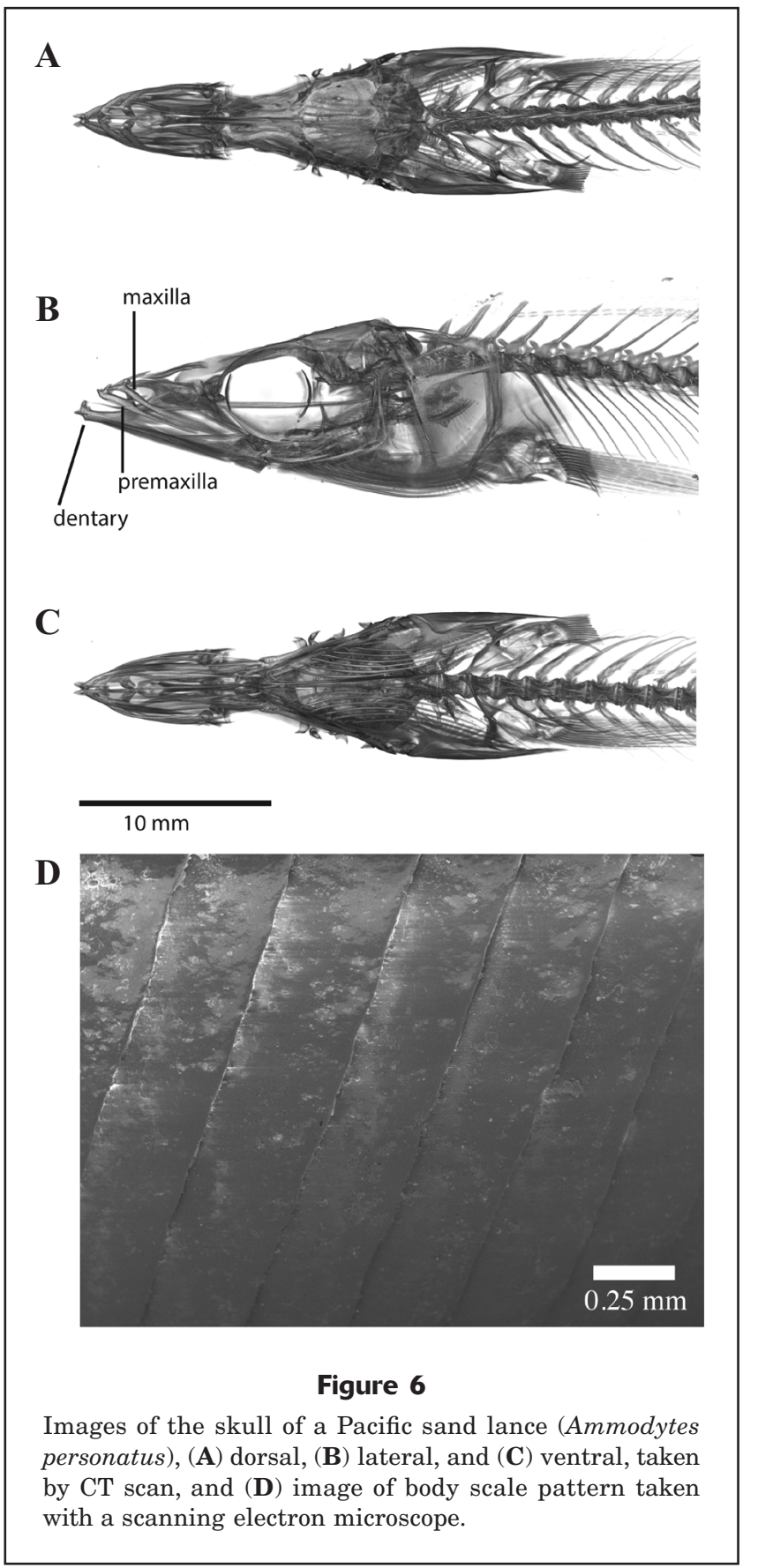

tidal (Haynes et al., 2007) and inner-continental-shelf (this study) regions, where uniform sediment types are uncommon; however, in both types of regions, coarse sands were dominant among heterogeneous sediment types. Furthermore, habitat associations of Pacific sand lance may indicate sediments that are used for foraging and for predator avoidance, in addition to those used for burial purposes (Hobson, 1986; Johnson et al., 2008; Robinson et al., 2013). Whereas swimming Pacific sand lance aggregate over a variety of substrate types as well as in open water, they consistently use habitats that are dominated by coarse sands for burial purposes.
Marine sand wave fields appear to serve as an important deepwater habitat refuge for Pacific sand lance. Sand wave fields are found on the continental shelf and inland waters in areas with a nearby source of sediment and a narrow range of high current velocities that remove the smaller clast sizes without carrying in larger gravels (Barrie et al., 2009). Their occurrence is therefore limited, but these seafloor features are more stable than intertidal and subtidal habitats of Pacific sand lance-habitats that are typically dynamic and often ephemeral (Parks et al., 2013). Our data indicated that preference for this comparatively rare substrate probably results from the typically high proportions of medium to coarse sand and consistent bottom currents that provide a steady flow of oxygen to unconsolidated substrates. More research incorporating a variety of grain sizes and seabed features is necessary to better determine the importance of sand wave fields as habitat of Pacific sand lance and to identify the characteristics that drive this association.

Potential burial habitat appears to be much broader than realized burial habitat for Pacific sand lance. It is well established that Ammodytes species prefer welldrained sediments (Robards and Piatt, 1999). Therefore, relatively small grain sizes that lack sufficient interstitial spaces for water flow are mainly avoided. In our laboratory experiments, most fish remained swimming when presented with uniform silt or fine sand substrates, and those fish that burrowed soon reoriented themselves so that their heads were exposed. This behavior also has been reported for the lesser sand eel (A. tobianus) under laboratory conditions. When subjected to decreasing sedimentary oxygen levels from normoxic to anoxic in fine sand, individual lesser sand eels moved closer to the sediment surface, eventually exposing their heads to facilitate respiration (Behrens et al., 2007). Pacific sand lance universally rejected silt when presented with other burial sediments (Pinto et al., 1984). The sand eel avoids sediments that contain $>10 \%$ silt or clay, and variation in its abundance has been negatively associated with the amount of sedimentary silt (Wright et al., 2000). Grain sizes smaller than medium sand generally are too poorly oxygenated to enable protracted burial by the Pacific sand lances and other Ammodytes species; therefore, respiratory tolerances influence sediment choice and limit the realized burial habitat of species of Ammodytes.

An upper boundary of grain size for burial of Pacific sand lance is more difficult to establish but appears to fall within the size range of gravel. A positive association between length and grain size was reported for the sand eel (Holland et al., 2005) and is supported by the results of our experiments on burial capability of Pacific sand lance. Some possible explanations for this association are that larger subadult and adult specimens, compared with smaller juvenile specimens, 1) can more easily generate the force necessary to penetrate gravels, 2) have greater respiration demands and require more well-drained sediments, and 3) are less susceptible to abrasion. The largest grain size used in this study, 
very fine gravel, was not commonly selected; however, the Pacific sand lance is able to use uniform very fine gravel (this study) and a mixture of very fine-to-medium gravel for long-term burial (Pinto et al., 1984). The force required or damage incurred by burial in increasingly coarse sediment will outweigh the benefit of increased water flow at some tolerance point, above which larger grain sizes will be avoided. Coarse sand with pebbles and fine-medium gravel have been reported as burial habitat for Ammodytes species (Robards and Piatt, 1999; Holland et al., 2005), but sediments dominated by coarse gravel, pebble, or cobble may represent such a boundary. More research is needed to determine the largest grain size or sizes of sediment that Pacific sand lance can use as burial habitat and how this tolerance varies with life stage and oxygen level.

Although clear sediment preferences were established, there was substantial variability in results among experimental trials that appears to be related to behavior. Even in trials where grain preference was marked, there was considerable inter-trial variability in the total number of fish that buried themselves. Additionally, the relative proportion of buried fish was highly variable among trials involving increasing grain sizes from coarse sand-very fine gravel. Intertrial variability was greatest between coarse sand and very coarse sand at night, possibly because it is more difficult for Pacific sand lance to distinguish between similar sediment types without visual cues. As reported by Pinto et al. (1984), Pacific sand lance did not burrow en masse. Instead, individuals buried themselves at different times and sometimes switched sediment types during a trial. Variability in burial preference among trials therefore seems to be related to the individual differences in behavior. This variability appears to be enhanced when sediment types of comparable preference are available.

Results of day and night experiments and field collections generally ran counter to the established diurnal burial pattern of Ammodytes species. Ammodytes species seek refuge in the seafloor at night to avoid predators, and they are typically active during the day (Robards and Piatt, 1999). However, when food is scarce (Winslade, 1974) or predators are active (Hobson, 1986), species of Ammodtyes also will burrow during the daytime. No food was provided to Pacific sand lance during trials, and the tank enclosure did not represent typical daytime feeding habitat, which is open water. A high proportion of Pacific sand lance may, therefore, have buried themselves during daylight hours to conserve energy or to reduce stress. Field collections indicated that substantially more Pacific sand lance were buried during the day than at night. This result may be an artifact of limited temporal and spatial sampling. Distribution of Pacific sand lance is known to be patchy (van der Kooij et al., 2008), and perhaps too few samples were collected to capture this spatial variability. There also may have been additional considerations, such as current flux or predator dynamics that influence the relative number of day and night burials. It also is possible that the diurnal pattern of habitat use that has been established for Ammodytes species is more complex or not directly attributable to Pacific sand lance. More research is needed to determine day and night use of deepwater habitats by Pacific sand lance.

Because of the importance of Pacific sand lance to regional trophic dynamics and the potential for anthropogenic disturbance of important burial grounds, determining and conserving preferred habitats of Pacific sand lance may be a future management consideration. There is no active fishery for Pacific sand lance in U.S. waters, and the main drivers of abundance of Ammodtyes species are environmental conditions and density dependence during early life stages (Arnott et al., 2002). However, fishing activities (especially bottom trawling) can change substrate composition, primarily by decreasing complexity and fluidizing sediment, generally leading to a proliferation of smaller grains sizes (e.g., muds instead of sands) (Auster et al., 1996). Other anthropogenic disturbance (e.g., dredging and sediment mining) also may alter sediment composition, reduce the amount of preferred sediment types, or cause direct mortality to populations of Pacific sand lance (Eleftheriou and Robertson, 1992).

The field techniques described in our study can be used with data that have been previously collected, newly accumulated from seafloor imagery, or bottomsampled in areas of interest to create and evaluate maps of potential habitat. Crucial habitats of Pacific sand lance can then be identified and conserved through establishment of marine protected areas or other notake zones. This type of applied research is currently being conducted on populations of Pacific sand lance in British Columbia (Robinson et al., 2013) and has important considerations for American populations of Pacific sand lance off Washington and in the Gulf of Alaska.

Different geological characteristics explained the variable amount of potential preferred and suitable habitat among fishing grounds in southeast Alaska. Preferred habitat for Pacific sand lance was predicted to be most abundant at Edgecumbe, where sand surrounds a recent lava flow in deep water (>120 m; Greene et al., 2007a). Small pockets of sand and gravel, including sand waves, occur on Fairweather Ground, as do a majority of sandy sediments (Greene et al., 2007b). These sands and gravels have been eroded from the extensive sandstone on the Fairweather Ground, and they account for the greatest amount of predicted preferred and suitable habitat among locations. Some of the preferred habitat of Pacific sand lance at Fairweather Ground is associated with a sand wave field that has been formed by an underlying syncline (Greene et al., 2007b). Dense aggregations of Pacific sand lance have been observed on this feature $\left(\right.$ Greene $\left.{ }^{3}\right)$, lending support to our predictions of preferred habitat. Much of the seafloor at Cape Ommaney consists of either rock, a mixture of granite and sand, or large, unconsolidated

\footnotetext{
${ }^{3}$ Greene, H. G. 2010. Personal commun. Friday Harbor Laboratories, Univ. Wash., Friday Harbor, WA 98250.
} 
grain sizes (gravel-cobble). Therefore, preferred habitat was predicted to be scarce at Cape Ommaney.

Overall, preferred habitat of Pacific sand lance was limited on the fishing grounds we examined off southeast Alaska. This result is not surprising because rock-associated species (e.g., tiger rockfish [Sebastes nigrocinctus]; yelloweye rockfish [Sebastes ruberrimus]; lingcod [Ophiodon elongates]) are the main targets of regional fisheries (Greene et al., 2011). However, Robinson et al. (2013), using a habitat suitability model that incorporated several physical variables, indicated that only 6\% of the study region in the Strait of Georgia was suitable habitat for Pacific sand lance. Our predictions, therefore, probably overestimate the amount of preferred and suitable habitat types on fishing grounds of southeast Alaska. The amount of preferred and suitable burial grounds would probably be reduced if more factors, such as depth and current speed, were considered in addition to grain size.

Our day and night experiments indicated that the Pacific sand lance does not rely exclusively on visual cues to assess habitat quality and that this species chooses sediments that are more difficult to penetrate in order to access preferred grain sizes. Some visual assessment of the substrate is supported by the equivalence of coarse and very coarse sand in night trials, but we have no explanation for the decrease in the variability in choice of sediment at night. Fish were often observed "nosing" the sediment before burrowing, and they may use tactile cues to determine grain size. We suppose that coarse sand provides a desired combination of ease of penetration and interstitial space that represents the best means for reducing the energetic costs of burrowing while maintaining access to oxygenated waters. This supposition was supported by our anecdotal observation that in medium sand and smaller grain sizes, fish often reoriented themselves after burrowing so that their entire head was exposed. Larger grain sizes may be too difficult to penetrate for subadult Pacific sand lance or may abrade the skin.

Burrowing in terrestrial environments usually is associated with elongation of the body, reduced eyes and limbs, and well-ossified skulls with fused elements (i.e., Summers and O'Reilly, 1997; Lee, 1998). Although the Pacific sand lance does have an elongate body, a small cross section, and fins that lie flat, it otherwise has little in common with typical burrowers. The $\mathrm{Pa}$ cific sand lance has prominent, large eyes, its skull is complex, and no mineralization is evident in several areas, including the dorsal region caudal to the maxilla. The lower jaw is well mineralized, but no more so than in fish species that do not burrow. Nevertheless, individuals of this species are able to bury themselves rapidly and in a wide variety of sediments. They can burrow for several body lengths and spend considerable periods of their lives under the substrate. There is evidence that they do not fluidize the sand in advance of penetration-a behavior that would have explained what appears to be poorly adapted morphological features for burrowing (Gidmark et al., 2011).
We are left to remark upon the sole morphological oddity for which we can imagine a burrowing function. The scales of the Pacific sand lance, and those of all species of Ammodytes, are unusual with respect to other fishes in that they are fused into bands that run roughly dorsoventrally. These bands are of taxonomic interest, although no function has ever been ascribed to them (Orr et al., 2015). We propose that the spacing of the scale bands interacts with the grain size of the substrate to produce a reduced frictional interaction between the fish and the sand. Indeed, movement was observed to be considerably more rapid for subadult Pacific sand lance in saturated coarse sand than in other grain sizes. Our supposition should be testable with nanoscale accurate replicas of the Pacific sand lance and may be modeled with contact mechanics in an unusual low-force regime (Persson and Scaraggi, 2014). Because of the variation in scale spacing on the body in different Ammodytes species and the change in spacing as an individual grows to maturity, the implication of a friction reducing system is that habitat preference of sand lances should vary with spacing on inter- and intraspecific bases.

Other habitat characteristics (e.g., depth, current velocity, oxygen content, particle sorting) are important, but none is a more fundamental driver of distribution and abundance of Pacific sand lance than grain size. Considerable laboratory and field evidence indicates that coarse sand sediments and mixtures of sediment that are dominated by coarse sand are preferred burial habitats for Pacific sand lance in the subadult and adult life stages from intertidal depths to at least $80 \mathrm{~m}$. Use of deepwater habitats, especially sand wave fields, are poorly understood but should be further evaluated because seafloor structure, current regimes, and other physical factors play an unknown role in habitat selection of Pacific sand lance. Determination of sediment preferences of the Pacific sand lance will be important for potential habitat-based management of this important forage species because trawling, dredging, and other anthropogenic disturbances may modify its preferred habitat. A link between form and function has been established for Pacific sand lance, in that this species appears to have a scale pattern that is adapted for rapid burial in coarse sand. Future research should focus on investigating the spacing of scale bands on the body for different sizes and species of Ammodytes and the role of such spacing in reducing friction during burial.

\section{Acknowledgments}

We thank T. Wyllie-Echeverria, P. Bourdillon, and the students of the 2010 and 2012 Functional Ecology and Morphology of Marine Fishes courses at Friday Harbor Laboratories for their assistance with this project. We also thank T. O'Connell, C. Brylinsky, and K. Green of the Alaska Department of Fish and Game for their prior collaborations with $\mathrm{H}$. Greene and the 
senior author that generated the substrate maps that we used to predict habitat quality of Pacific sand lance. A. Stone provided inspiration for the successful completion of this project. The North Pacific Research Board (Project 1207), National Science Foundation (IOS-1256602), Friday Harbor Laboratories, and Northwest Straits Commission provided financial support for our research.

\section{Literature cited}

Arnott, S. A., G. D. Ruxton, and E. S. Poloczanska.

2002. Stochastic dynamic population model of North Sea sandeels, and its application to precautionary management procedures. Mar. Ecol. Prog. Ser. 235:223-234. Article

Auster, P. J., R. J. Malatesta, R. W. Langton, L. Watling, P. C. Valentine, C. L. S. Donaldson, E. W. Langton, A. N. Shepard, and W. G. Babb.

1996. The impacts of mobile fishing gear on seafloor habitats in the Gulf of Maine (Northwest Atlantic): implications for conservation of fish populations. Rev. Fish. Sci. 4:185-202. Article

Barrie, J. V., K. W. Conway, K. Picard, and H. G. Greene.

2009. Large-scale sedimentary bedforms and sediment dynamics on a glaciated tectonic continental shelf: examples from the Pacific margin of Canada. Cont. Shelf Res. 29:796-806. Article

Beacham, T. D.

1986. Type, quantity, and size of food of Pacific salmon (Oncorhynchus) in the Strait of Juan de-Fuca, British Columbia, Canada. Fish. Bull. 84: 77-90.

Behrens, J. W., H. J. Stahl, J. F. Steffensen, and R. N. Glud. 2007. Oxygen dynamics around buried lesser sandeels Ammodytes tobianus (Linneaus 1785): mode of ventilation and oxygen requirements. J. Exp. Biol. 210:1006-1014. Article

Bertram, D. F., and G. W. Kaiser.

1993. Rhinoceros auklet (Cerorhinca moncerata) nestling diet may gauge Pacific sand lance (Ammodytes hexapterus) recruitment. Can. J. Fish. Aquat. Sci. 50:1908-1915. Article

Borstad, G., W. Crawford, J. M. Hipfner, R. Thompson, and K. Hyatt.

2011. Environmental control of breeding success of rhinoceros auklets at Triangle Island, British Columbia. Mar. Ecol. Prog. Ser. 424:285-302. Article

Connallon, T., and E. Jakubowski.

2009. Association between sex ratio distortion and sexually antagonistic fitness consequences of female choice. Evolution 63:2179-2183. Article

Curry, P. M., I. L. Boyd, S. Bonhommeau, T. Anker-Nilssen, R. J. M. Crawford, R. W. Furness, J. A. Mills, E. J. Murphy, H. Osterblom, M. Paleczny et al.

2011. Global seabird response to forage fish depletionone third for the birds. Science 334:1703-1706. Article

de Beer, D., F. Wenzhöfer, T. G. Ferdelman, S. E. Boehme, M.

Huettel, J. E. E. van Beusekom, M. E. Böttcher, N. Musat, and N. Dubilier.

2005. Transport and mineralization rates in North Sea sandy intertidal sediments, Sylt-Røm $\emptyset$ Basin, Wadden Sea. Limnol. Oceanogr. 50:113-127. Article
Eleftheriou, A., and M. R. Robertson.

1992. The effects of experimental scallop dredging on the fauna and physical environment of a shallow sandy community. Netherlands J. Sea Res. 30:289-299. Article

Essington, T. E., P. E. Moriarity, H. E. Froehlich, E. E. Hodgson, L. E. Koehn, K. L. Oken, M. C. Siple, and C. C. Stawitz. 2015. Fishing amplifies forage fish population collapses. Proc. Natl. Acad. Sci. U.S.A. 112:6648-6652. Article

Frederiksen, M., H. Jensen, F. Daunt, R. A. Mavor, and S. Wanless.

2008. Differential effects of a local industrial sand lance fishery on seabird breeding performance. Ecol. Appl. 18:701-710.

Freeman, S., S. Mackinson, and R. Flatt.

2004. Diel patterns in the habitat utilisation of sandeels revealed using integrated acoustic surveys. J. Exp. Mar. Biol. Ecol. 305:141-154. Article

Friedlaender, A. S., E. L. Hazen, D. P. Nowacek, P. N. Halpin, C. Ware, M. T. Weinrich, T. Hurst, and D. Wiley.

2009. Diel changes in humpback whale Megaptera novaeangliae feeding behavior in response to sand lance $\mathrm{Am}$ modytes spp. behavior and distribution. Mar. Ecol. Prog. Ser. 395:91-100. Article

Gaichas, S. K., K. Y. Aydin, and R. C. Francis.

2010. Using food web model results to inform stock assessment estimates of mortality and production for ecosystem-based fisheries management. Can. J. Fish. Aquat. Sci. 67:1490-1506. Article

Gidmark, N. J., J. A. Strother, J. M. Horton, A. P. Summers, and E. L. Brainerd.

2011. Locomotory transition from water to sand and its effects on undulatory kinematics in sand lances (Ammodytidae). J. Exp. Biol. 214:657-664. Article

Godersky, A., and A. P. Summers. 2016. Ammodytes personatus neotype slice data.

Greene, H. G., V. M. O'Connell, W. W. Wakefield, and C. K. Brylinsky.

2007a. The offshore Edgecumbe lava field, southeast Alaska: geologic and habitat characterization of a commercial fishing ground. In Mapping the seafloor for habitat characterization (B. J. Todd and H. G. Greene, eds.), p. 251-270. Geol. Assoc. Canada, St. Johns, Canada.

Greene, H. G., J. J. Bizzarro, V. M. O'Connell, and C. K. Brylinsky.

2007b. Construction of digital potential marine benthic habitat maps using a coded classification scheme and its application. In Mapping the seafloor for habitat characterization (B. J. Todd and H. G. Greene, eds.), p. 145160. Geol. Assoc. Canada, St. Johns, Canada.

Greene, H. G., V. M. O'Connell, and C. K. Brylinsky.

2011. Tectonic and glacial related seafloor geomorphology as possible demersal shelf rockfish habitat surrogatesexamples along the Alaskan convergent transform boundary. Cont. Shelf Res. 31:S39-S53. Article

Han, Z., T. Yanagimoto, Y. Zhang, and T. Gao.

2012. Phylogeography study of Ammodytes personatus in northwestern Pacific: Pleistocene isolation, temperature and current conducted secondary contact. PLoS ONE 7(5): e37425. Article

Haynes, T. B., R. A. Ronconi, and A. E. Burger.

2007. Habitat use and behavior of the Pacific sand lance (Ammodytes hexapterus) in the shallow subtidal region of southwestern Vancouver Island. Northwest. Nat. 88:155-167. Article 
Hobson, E. S.

1986. Predation on the Pacific sand lance, Ammodytes hexapterus (Pisces: Ammodytidae), during the transition between day and night in southeastern Alaska. Copeia $1: 223-226$.

Høines, Å. S., and O. A. Bergstad.

2001. Density of wintering sand eel in the sand recorded by grab catches. Fish. Res. 49:295-301. Article

Holland, G. J., S. P. R. Greenstreet, I. M. Gibb, H. M. Fraser, and M. R. Robertson.

2005. Identifying sandeel Ammodytes marinus sediment habitat preferences in the marine environment. Mar. Ecol. Prog. Ser. 303:269-282. Article

Johnson, S. W., J. F. Tehdinga, and K. M. Munk.

2008. Distribution and use of shallow-water habitats by Pacific sand lances in Southeastern Alaska. Trans. Am. Fish. Soc. 137:1455-1463. Article

Kleinteich, T., H. C. Maddin, J. Herzen, F. Beckmann, and A. P. Summers.

2012. Is solid always best? Cranial performance in solid and fenestrated caecilian skulls. J. Exp. Biol. 215:833844. Article

Lee, M. S. Y.

1998. Convergent evolution and character correlation in burrowing reptiles: towards a resolution of squamate relationships. Biol. J. Linn. Soc. 65:369-453. Article

Love, M. S., C. W. Mecklenburg, T. A. Mecklenburg, and L.K. Thorsteinson.

2005. Resource inventory of marine and estuarine fishes of the West Coast and Alaska: a checklist of North Pacific and Arctic Ocean species from Baja California to the Alaska-Yukon border, 276 p. U.S. Geological Survey, Seattle. [Available at website.]

Macer, C. T.

1966. Sand eels (Ammodytidae) in the south-western North Sea: their biology and fishery. Great Britain Minist. Agric. Fish. Food, Fish. Invest. Ser, II Mar. Fish. 24, 55 p. Her Majesty's Stationary Office, London.

Maladen, R. D., Y. Ding, C. Li, and D. I. Goldman.

2009. Undulatory swimming in sand: subsurface locomotion of the sandfish lizard. Science 325:314-318. Article

Maladen, R. D., Y. Ding, P. B. Umbanhowar, A. Kamor, and D. I. Goldman.

2011. Mechanical models of sandfish locomotion reveal principles of high performance subsurface sand-swimming. J. R. Soc. Interface 8:1332-1345. Article

McDonald, J. H.

2009. Handbook of biological statistics, 2nd ed., 319 p. Sparky House Publishing, Baltimor, MD.

Mecklenburg, C. W., P. R. Moller, and D. Steinke.

2011. Biodiversity of arctic marine fishes: taxonomy and zoogeography. Mar. Biodivers. 41:19-140. Article

Mushinsky, H. R., and C. Gans.

1992. The role of the tail in channel passage by the sand skink, Neoseps reynoldsi. Amphibia-Reptilia 13:393403. Article

Nelson, G. A., and M. R. Ross.

1991. Biology and population change of northern sand lance (Ammodytes dubius) from the Gulf of Maine to Middle Atlantic Bight. J. Northwest Atl. Fish. Sci. $11: 11-28$.

Orr, J. W., S. Wildes, Y. Kai, N. Raring, T. Nakabo, O. Katugin, and J. Guyon.

2015. Systematics of North Pacific sand lances of the genus Ammodytes based on molecular and morphometric evidence, with the description of a new species from Japan. Fish. Bull. 113:126-156. Article
Ohshima, Y.

1950. Biological notes on the sand-eel Ammodytes personatus Girard. Nippon Suisan Gakkaishi 16:99-107 Article

Ostrand, W. D., T. A. Gotthardt, S. Howlin, and M. D. Robards. 2005. Habitat selection models for Pacific sand lance (Ammodytes hexapterus) in Prince William Sound, Alaska. Northwestern Naturalist 86:31-143.

Parks, D., A. Shaffer, and D. Barry.

2013. Nearshore drift-cell sediment processes and ecological function for forage fish: implications for ecological restoration of impaired Pacific Northwest marine ecosystems. J. Coast. Res. 29:984-997. Article

Persson, B. N. J., and M. Scaraggi.

2014. Theory of adhesion: role of surface roughness. J. Chem. Phys. 141:124701. Article

Pinto, J. M., W. H. Pearson, and J. W. Anderson.

1984. Sediment preferences and oil contamination in the $\mathrm{Pa}-$ cific sand lance Ammodytes hexapterus. Mar. Biol. 83:193204. Article

Richardson, D. E., M. C. Palmer, and B. E. Smith.

2014. The influence of forage fish abundance on the aggregation of Gulf of Maine Atlantic cod (Gadus morhua) and their catchability in the fishery. Can. J. Fish. Aquat. Sci. 71:1349-1362. Article

Robards, M. D., and J. F. Piatt.

1999. Biology of the genus Ammodytes, the sand lances. In Sand lance: a review of biology and predator relations and annotated bibliography (M. D. Robards, M. F. Wilson, R. H. Armstrong, and J. F. Piatt, eds.), p. 1-16. U.S. Dep. Agric., Forest Serv., Seattle, WA.

Robinson, C. L. K., D. Hrynyk, J. V. Barrie, and J. Schweigert. 2013. Identifying subtidal burying habitat of Pacific sand lance (Ammodytes hexpaterus) in the Strait of Georgia, British Columbia, Canada. Prog. Oceanogr. 115:119128. Article

Rose, J. A., M. Sandefur, S. Huskey, J. L. Demler, and M. T. Butcher.

2013. Muscle architecture and out-force potential of the thoracic limb in the eastern mole (Scalopus aquaticus). J. Morphol. 274:1277-1287. Article

Smith, A. D. M., C. J. Brown, C. M. Bulman, E. A. Fulton, P. Johnson, I. C. Kaplan, H. Lozano-Montes, S. Makinson, M. Marzloff, L. J. Shannon, et al.

2011. Impacts of fishing low-trophic level species on marine ecosystems. Science 333:1147-1150. Article

Summers, A. P., and J .C. O'Reilly.

1997. A comparative study of locomotion in the caecilians Dermophis mexicanus and Typhlonectes natans (Amphibia: Gymnophiona). Zool. J. Linn. Soc. 121:65-76. Article

Turanov, S. V., and Y. P. Kartavtsev.

2014. The taxonomic composition and distribution of sand lances from the genus Ammodytes (Perciformes: Ammodytidae) in the North Pacific. Russ. J. Mar. Biol. 40:447-454. Article

van der Kooij, J., B. E. Scott, and S. Mackinson.

2008. The effects of environmental factors on daytime sandeel distribution and abundance on Dogger Bank. J. Sea Res. 60:201-209. Article

Weinrich, M., M. Martin, R. Griffiths, J. Bove, and M. Schilling. 1997. A shift in distribution of humpback whales, Megaptera novaengliae, in response to prey in the southern Gulf of Maine. Fish. Bull. 95:826-836.

Wentworth, C. K.

1922. A scale of grade and class terms for clastic sediments. J. Geol. 30:377-392. 
Winslade, P.

1974. Behavioural studies on the lesser sandeel Ammodytes marinus (Raitt). II. The effect of light intensity on activity. J. Fish Biol. 6:577-586. Article
Wright, P. J., H. Jensen, and I. Tuck.

2000. The influence of sediment type on the distribution of the lesser sandeel, Ammodytes marinus. J. Sea Res. 44:243-256. Article 